\title{
Depression in the Context of Search of a New Paradigm in Psychiatry
}

Rosman $\mathrm{SV}^{1^{*}}$ and Maximova $\mathrm{NE}^{2}$

${ }^{1}$ Physician of Functional Diagnostics of SBIH, Regional Psychoneurological Clinic, Russia

${ }^{2}$ Department of Psychiatry of the SBEI, Tver State Medical University, Ministry of Health of Russia, Russia

*Corresponding author: Rosman SV, Physician of Functional Diagnostics of SBIH, Regional Psychoneurological Clinic, Tver, Russian Federation, Russia, Tel: +7-903-800-11-05; E-mail: seros2005@mail.ru

Received date: July 30, 2018; Accepted date: August 13, 2018; Published date: August 21, 2018

Copyright: ( 2018 Rosman SV et al. This is an open-access article distributed under the terms of the Creative Commons Attribution License, which permits unrestricted use, distribution, and reproduction in any medium, provided the original author and source are credited.

\begin{abstract}
By means of a new method - dispersions of amplitude-frequency characteristics of an alpha rhythm of EEG are given proofs that the depression is the symptom characterizing exhaustion of the mechanisms stabilizing functional ability of Neuron-Glial Network of the brain with formation of a functional gipofrontalnost and is a marker of transition of pathological process to an organic phase. This process is a link in a chain of search of a new paradigm of the psychiatry, which is based that the psychopathology is result of disorganization of Neuron-Glial Network of the brain.
\end{abstract}

Keywords: Depression; Dispersion of alpha rhythm; Paradigm of psychiatry

\section{Abbreviations:}

BPD: Borderline Personality Disorder; BHD: Borderline Hypofrontality Disorder; NGNB: Neuron-Glial Network of the Brain; CDal: Coefficient of Dispersion of Alpha-Rhythm EEG-1 (the quotient of the modal values of power of alpha rhythm to his total power in the range of 7-13 Hz); DAFCAR: Dispersion of Amplitude-Frequency Characteristics of the Alpha Rhythm EEG; CDal: Coefficient of Dispersion of Alpha-Rhythm EEG-1 (the quotient of the modal values of power of alpha rhythm to his total power in the range of 7-13 Hz); CDa2: Coefficient of Dispersion of the Alpha-Rhythm EEG-2 (the quotient of the power of the alpha rhythm in the range of "a modal value $\pm 0.5 \mathrm{~Hz}^{\prime \prime}$ to his total power in the range of 7-13 Hz); Mo f O: Value of the Modal Frequencies in Occipital Electrodes; Mo f F: Value of the Modal Frequencies in Frontal Electrodes; $\Delta \mathrm{Mo} f(\mathrm{O} 1 ; \mathrm{F} 3)-(\mathrm{Mo} \mathrm{f}$ $\mathrm{O}$ - Mo f F): Value of the Difference of Modal Frequencies Between the Occipital and Frontal Electrodes; As(O1): Value of the Asymmetry Distribution CDal in the Occipital Electrodes; $\operatorname{Ex}(\mathrm{O} 1)$ : Value of the Kurtosis of the Normal Distribution CDal in the Occipital Electrodes; As(F3): Value of the Asymmetry Distribution CDal in the Frontal Electrodes; $\operatorname{Ex}(\mathrm{F} 3)$ : Value of the Kurtosis of the Normal Distribution $\mathrm{CDal}$ in the Frontal Electrodes; $\Delta \mathrm{As}(\mathrm{O} 1 ; \mathrm{F} 3)$ : Value of the Difference of Asymmetry Distribution CDal Between the Occipital and Frontal Electrodes; $\triangle \operatorname{Ex}(\mathrm{O} 1 ; \mathrm{F} 3)$ : Value of the Difference of Kurtosis Distribution CDal Between the Occipital and Frontal Electrodes; IZ: Index of Zonality-Distribution of power of an Alpha Rhythm between Departments of a Brain; CI: Confidence Interval; CV: Coefficient of Variation

\section{Introduction}

The importance of a depression in psychiatry is huge. By estimates of some researchers not less than $10 \%$ of the population, are more senior than 40 years, has this mental disorder, and at advanced age-is 3 times more. Not less than $5 \%$ of children and teenagers test a condition of a depression, and some, without maintaining subjective experiences, make suicidal acts. All these problems are repeatedly described, and there is no big sense all this to remind especially as it doesn't result us in the true cause of a depression. Numerous researches in the field of an etiology of a depression have led, generally to search of antidepressants which, reducing expressiveness of subjective feelings of the patient, don't lead to elimination of an etiological factor [1].

The main problem of psychiatry is especially categorical approach. It means that on the basis of symptoms of mental diseases of researchers speculative concepts of pat psychological phenomena which set is the diagnosis are under construction. The community of psychiatrists estimates repeatability of these sets in practice systematizes them and applies in daily activity. It is easy to understand that such subjective approach is very vulnerable as to the place of search of a cause of illness manipulations with his symptoms come. It is easy to imagine what would be if we treated diabetes only, analyzing subjective feelings of the patient, but not measuring glucose level at him in blood.

At the same time dimensional approach in psychiatry the reason of it at all not that on the way of this search insuperable technical difficulties lie doesn't find due application, and. The main reason-in unwillingness to leave from the convenient and uncontrolled system of diagnostics in psychiatry. Modern systematization of mental diseases (MKB) - bright to that the proof. Infinite regroupings of psychopathology, any inclusion and an exception of her of nosological forms to please to a political environment - all this signs that systematization of mental diseases isn't based on a natural-science basis, and is result of manipulation with subjective representations of psychiatrists [2].

Recently there were attempts of connection of the categorical and dimensional directions in medicine, as is fundamentals of evidential medicine. But on this way there is a big problem-numerous attempts to find correlation connections with violations in a brain weren't crowned with resolute success. In other words, it is impossible to tell unambiguously what structure in a brain is damaged at a depression, as well as at other mental diseases $[3,4]$.

In the solution of such complex problems as a depression, it is impossible to stop on one concept, for example, of deficiency of serotonin and to base on it all technique of diagnostics and treatment. 
Page 2 of 9

In this article, without disproving the available ideas of the depression reasons, additional ways of judgment of their reason, based on new ideas of a role of neural and glial network of a brain are offered.

The initial idea is idea that a depression-not an independent disease, but a symptom, like pain at cancer. The depression signals that Neuron-Glial Network of the brain is disorganized as a result of pathological influence, for example, of a stressful factor or a vascular disorder.

The main objective of an organism is providing a homeostasis. Functional systems have to work in certain, sometimes enough strictly established, borders. For example, $\mathrm{pH}$ of blood is normal - 7,36-7,44, an exit for these borders leads to heavy consequences. The same belongs and to parameters of activity of Neuron-Glial Network of the brain-EEG alpha rhythm frequency deviation between frontal and occipital departments in $0,25 \mathrm{~Hz}$ leads to notable behavioural violations, and at a difference in $1 \mathrm{~Hz}$ there comes schizophrenia. Synchronization of activity of Neuron-Glial Network of the brain is important homeostatic function of an organism, and it is carried out with the help of stressful hormones.

Pathological impacts on a brain, in particular psych injuries, will disorganize Neuron-Glial Network of the brain, additional resources which aren't infinite begin to be spent for restoration of synchronization of her activity. There comes the deficiency of mechanisms of regulation of synchronization of activity of NeuronGlial Network of the brain, which is shown, in particular, by a depression.

Communication of disorganization of Neuron-Glial Network of the brain and depression easily explains presence of a depression at children and old men. According to inspection of children in one of clinics of Moscow it is revealed that at them the condition of disorganization of Neuron-Glial Network of the brain owing to imperfection of process of "a neurophysiological overkloking" - the phenomena of normal increase of frequency of an alpha rhythm of EEG in the course of neurophysiological maturing of a brain comes to light rather often. The frequent fact is its unevenness in various departments, as is the reason of disorganization of Neuron-Glial Network of the brain. At old men vascular pathology owing to atherosclerosis and other exchange violations is the main reason for disorganization of Neuron-Glial Network of the brain. By the way, the similar mechanism of a depression at alcoholics, but the basic is violation of trophic processes owing to violation of rheological properties of blood and micro blood circulation in brain structures under the influence of alcohol here.

All these theoretical prerequisites demand practical proofs, and the present article is one of milestones on this way.

The purpose of the study: To prove that one of the reasons of a depression is disorganization of functional ability of Neuron-Glial Network of the brain, which marker are changes of indicators of DAFCAR.

\section{Materials and Methods}

The standard technique of performance of EEG with an arrangement of electrodes on the international system "10-20\%" and ipsilateral ear electrodes was carried out. Test from a hyperventilation was carried out by a standard technique with dispersive assessment of changes of an alpha rhythm method of Rosman. The DAFCAR parameters were calculated by method of Rosman by means of the Microsoft Excel and Statistica programs 12.0 [4-8].

\begin{tabular}{|l|l|l|l|l|l|}
\hline Nosological forms & Women & Age & Men & Age & Total \\
\hline Depressia (F3x) & 41 & $36(31-40)$ & 30 & $36(31-41)$ & 71 \\
\hline BPD(F06.x, F60.x) & 69 & $26(22-30)$ & 199 & $25(23-26)$ & 268 \\
\hline Health & 20 & $34.1 \pm 0.5$ & 57 & $21(20-23)$ & 77 \\
\hline Total & $\mathbf{1 3 0}$ & & $\mathbf{2 8 6}$ & & $\mathbf{4 1 6}$ \\
\hline
\end{tabular}

Table 1: Distribution of patients on groups.

\section{Results}

For researches young people and middle age patients for an exception of influence of age changes, with the minimum possibility of the accompanying pathology and minimization of vrednost are selected. All patients the research was carried out during performing therapy by psychotropic and sedative drugs. Distribution of patients on groups is presented in Tables 1-5.

\begin{tabular}{|c|c|c|c|c|c|c|c|}
\hline \multirow[t]{3}{*}{ Gender } & \multirow[t]{3}{*}{ Index DAFCAR } & \multicolumn{2}{|l|}{ F3x } & \multicolumn{2}{|l|}{ Health } & \multicolumn{2}{|l|}{ BPD } \\
\hline & & \multirow{2}{*}{$\begin{array}{l}\text { Mean } \\
\mathrm{Cl}\end{array}$} & \multirow[t]{2}{*}{$C V, \%$} & Mean & \multirow[t]{2}{*}{$C V, \%$} & Mean & \multirow[t]{2}{*}{$C V, \%$} \\
\hline & & & & $\mathrm{Cl}$ & & $\mathrm{Cl}$ & \\
\hline \multirow[t]{3}{*}{ Men } & \multirow[t]{2}{*}{ Mo f(O1) } & 9.69 & 8.93 & 10.25 & 5.48 & 9.94 & 7.91 \\
\hline & & $9.37-10.01$ & & $10.11-10.4$ & & $9.83-10.06$ & \\
\hline & $\operatorname{Mo} f(F 3)$ & 9.24 & 11.42 & 10.25 & 5.54 & 9.72 & 9.68 \\
\hline
\end{tabular}


Citation: Rosman SV (2018) Depression in the Context of Search of a New Paradigm in Psychiatry. Clin Depress 4: 134. doi: 10.4172/2572-0791.1000134

Page 3 of 9

\begin{tabular}{|c|c|c|c|c|c|c|c|}
\hline & & $8.85-9.64$ & & $10.1-10.41$ & & $9.58-9.86$ & \\
\hline & Mo $f(01 ; F 3)$ & 0.53 & 145.51 & 0.04 & 249.69 & 0.29 & 236.99 \\
\hline & & $0.24-0.82$ & & $0.01-0.06$ & & $0.19-0.4$ & \\
\hline & $\mathrm{As}(\mathrm{O} 1)$ & 1.91 & 48.53 & 2.66 & 12.86 & 2.09 & 35.84 \\
\hline & & $1.56-2.26$ & & $2.57-2.75$ & & $1.98-2.21$ & \\
\hline & $\operatorname{Ex}(\mathrm{O} 1)$ & 3.93 & 119.7 & 6.93 & 32.16 & 4.51 & 81.81 \\
\hline & & $2.17-5.69$ & & $6.34-7.52$ & & $3.95-5.07$ & \\
\hline & $\mathrm{As}(\mathrm{F} 3)$ & 1.66 & 58.96 & 2.59 & 16.87 & 1.74 & 48.83 \\
\hline & & $1.29-2.02$ & & $2.48-2.71$ & & $1.61-1.87$ & \\
\hline & $\mathrm{Ex}(\mathrm{F} 3)$ & 3.48 & 114.38 & 6.86 & 36.56 & 3.39 & 102.34 \\
\hline & & $1.99-4.97$ & & $6.19-7.52$ & & $2.87-3.91$ & \\
\hline & $\Delta \mathrm{As}(\mathrm{O} 1 ; \mathrm{F} 3)$ & 0.03 & $>1000$ & 0.02 & 773.65 & 0.11 & 464.2 \\
\hline & & -0.57 & & -0.08 & & $0.03-0.18$ & \\
\hline & $\Delta \mathrm{Ex}(\mathrm{O} 1 ; \mathrm{F} 3)$ & 0.46 & 466.71 & -0.04 & $<-1000$ & 1.53 & 798.66 \\
\hline & & -1.59 & & -0.2 & & -3.7 & \\
\hline & IZ & 0.14 & 101.07 & 0.13 & 75.76 & 0.15 & 90.5 \\
\hline & & $0.09-0.2$ & & $0.11-0.16$ & & $0.13-0.17$ & \\
\hline & Age & 36 & 36 & 21 & 22 & 25 & 41 \\
\hline & & $31-41$ & & $20-23$ & & $23-26$ & \\
\hline Women & Mo $f(01)$ & 9.65 & 11.9 & 10.2 & 3.86 & 9.79 & 12.4 \\
\hline & & $9.29-10.01$ & & $10.02-10.38$ & & $9.34-10.25$ & \\
\hline & $\operatorname{Mo} f(F 3)$ & 9.2 & 14.09 & 10.16 & 4.17 & 9.33 & 11.97 \\
\hline & & $8.79-9.61$ & & $9.96-10.36$ & & $8.92-9.75$ & \\
\hline & Mo $f(01 ; F 3)$ & 0.61 & 139.05 & 0.04 & 244.23 & 0.48 & 231.43 \\
\hline & & $0.34-0.88$ & & -0.09 & & $0.06-0.89$ & \\
\hline & $\mathrm{As}(\mathrm{O} 1)$ & 1.65 & 41.48 & 2.6 & 10.04 & 2.16 & 34.88 \\
\hline & & $1.43-1.86$ & & $2.48-2.73$ & & $1.88-2.44$ & \\
\hline & $\mathrm{Ex}(\mathrm{O} 1)$ & 2.47 & 112.67 & 6.56 & 26.19 & 5.24 & 64.45 \\
\hline & & $1.59-3.35$ & & $5.76-7.36$ & & $3.98-6.5$ & \\
\hline & $\mathrm{As}(\mathrm{F} 3)$ & 1.43 & 58 & 2.35 & 19.29 & 1.64 & 65.01 \\
\hline & & $1.17-1.69$ & & $2.14-2.57$ & & $1.24-2.04$ & \\
\hline & $\operatorname{Ex}(\mathrm{F} 3)$ & 2.24 & 148.31 & 5.43 & 44.67 & 3.41 & 120.29 \\
\hline & & $1.19-3.29$ & & $4.3-6.57$ & & $1.88-4.94$ & \\
\hline & $\Delta \mathrm{As}(\mathrm{O} 1 ; \mathrm{F} 3)$ & 0.08 & 668.24 & 0.1 & 139.38 & 0.15 & 539.63 \\
\hline & & -0.35 & & $0.03-0.16$ & & -0.59 & \\
\hline & $\Delta \operatorname{Ex}(01 ; \mathrm{F} 3)$ & -0.01 & $<-1000$ & 0.18 & 134.09 & 0.51 & 189.56 \\
\hline
\end{tabular}


Citation: Rosman SV (2018) Depression in the Context of Search of a New Paradigm in Psychiatry. Clin Depress 4: 134. doi: $10.4172 / 2572-0791.1000134$

Page 4 of 9

\begin{tabular}{|l|l|l|l|l|l|l|}
\hline \multirow{3}{*}{ IZ } & -1.49 & & $0.07-0.3$ & & $0.15-0.87$ & \\
\hline \multirow{2}{*}{ Age } & 0.15 & 69.15 & 0.12 & 73.18 & 0.17 & 71.24 \\
\cline { 2 - 8 } & $0.12-0.18$ & & $0.08-0.16$ & 38 & 26 & $0.12-0.21$ \\
\\
\cline { 2 - 8 } & 36 & 39 & 28 & & $22-30$ & 42 \\
\hline
\end{tabular}

Table 2: The summary table of the DAFCAR indexes at a depression (F3x on ICD-10, BHD) in comparison with sick boundary mental diseases (BPD) and healthy (Health). Left hemisphere.

\begin{tabular}{|c|c|c|c|c|c|c|c|}
\hline \multirow[t]{3}{*}{ Gender } & \multirow[t]{3}{*}{ Index DAFCAR } & \multicolumn{2}{|l|}{ F3x(BHD) } & \multicolumn{2}{|l|}{ Health } & \multicolumn{2}{|l|}{ BPD } \\
\hline & & \multirow{2}{*}{$\begin{array}{l}\text { Mean } \\
\mathrm{Cl}\end{array}$} & \multirow[t]{2}{*}{$\mathrm{CV}, \%$} & \multirow{2}{*}{$\begin{array}{l}\text { Mean } \\
\mathrm{Cl}\end{array}$} & \multirow[t]{2}{*}{ CV,\% } & \multirow{2}{*}{$\begin{array}{l}\text { Mean } \\
\mathrm{Cl}\end{array}$} & \multirow[t]{2}{*}{$\mathrm{CV}, \%$} \\
\hline & & & & & & & \\
\hline \multirow[t]{22}{*}{ Men } & Mo $f(O 2)$ & 9.71 & 8.95 & 10.27 & 5.49 & 9.96 & 7.93 \\
\hline & & $9.39-10.03$ & & $10.13-10.42$ & & $9.85-10.08$ & \\
\hline & Mo f(F4) & 9.27 & 11.45 & 10.28 & 5.56 & 9.75 & 9.71 \\
\hline & & $8.88-9.67$ & & $10.13-10.44$ & & $9.61-9.89$ & \\
\hline & Mo f(O2;F4) & 0.55 & 151.33 & 0.04 & 259.68 & 0.3 & 246.47 \\
\hline & & $0.25-0.85$ & & $0.01-0.06$ & & $0.2-0.42$ & \\
\hline & $\mathrm{As}(\mathrm{O} 2)$ & 1.95 & 49.5 & 2.71 & 13.12 & 2.13 & 36.56 \\
\hline & & $1.59-2.31$ & & $2.62-2.81$ & & $2.02-2.25$ & \\
\hline & $\operatorname{Ex}(\mathrm{O} 2)$ & 3.89 & 118.5 & 6.86 & 31.84 & 4.46 & 80.99 \\
\hline & & $2.15-5.63$ & & $6.28-7.44$ & & $3.91-5.02$ & \\
\hline & $\mathrm{As}(\mathrm{F} 4)$ & 1.74 & 61.91 & 2.72 & 17.71 & 1.83 & 51.27 \\
\hline & & $1.35-2.12$ & & $2.6-2.85$ & & $1.69-1.96$ & \\
\hline & $\operatorname{Ex}(\mathrm{F} 4)$ & 3.45 & 113.24 & 6.79 & 36.19 & 3.36 & 101.32 \\
\hline & & $1.97-4.92$ & & $6.13-7.44$ & & $2.84-3.87$ & \\
\hline & $\Delta \mathrm{As}(\mathrm{O} 2 ; \mathrm{F} 4)$ & 0.03 & 3040.7 & 0.02 & 789.12 & 0.11 & 473.48 \\
\hline & & -0.59 & & -0.08 & & $0.03-0.18$ & \\
\hline & $\Delta \operatorname{Ex}(\mathrm{O} 2 ; \mathrm{F} 4)$ & 0.47 & 480.71 & -0.04 & -1049.8 & 1.58 & 822.62 \\
\hline & & -1.64 & & -0.2 & & -3.81 & \\
\hline & $\mathrm{IZ}$ & 0.15 & 105.11 & 0.14 & 78.79 & 0.16 & 94.12 \\
\hline & & $0.09-0.21$ & & $0.11-0.17$ & & $0.14-0.18$ & \\
\hline & Age & 36 & 36 & 21 & 22 & 25 & 41 \\
\hline & & $31-41$ & & $20-23$ & & $23-26$ & \\
\hline \multirow[t]{4}{*}{ Women } & Mo $f(O 2)$ & 9.67 & 11.92 & 10.22 & 3.87 & 9.81 & 12.42 \\
\hline & & $9.31-10.03$ & & $10.04-10.4$ & & $9.36-10.27$ & \\
\hline & Mo $f(F 4)$ & 9.23 & 14.13 & 10.19 & 4.18 & 9.36 & 12.01 \\
\hline & & $8.82-9.64$ & & $9.99-10.39$ & & $8.95-9.78$ & \\
\hline
\end{tabular}


Citation: Rosman SV (2018) Depression in the Context of Search of a New Paradigm in Psychiatry. Clin Depress 4: 134. doi: $10.4172 / 2572-0791.1000134$

Page 5 of 9

\begin{tabular}{|c|c|c|c|c|c|c|}
\hline Mo $f(O 2 ; F 4)$ & 0.61 & 139.61 & 0.04 & 245.21 & 0.48 & 232.36 \\
\hline & $0.34-0.88$ & & -0.09 & & $0.06-0.89$ & \\
\hline $\mathrm{As}(\mathrm{O} 2)$ & 1.73 & 43.55 & 2.73 & 10.54 & 2.27 & 36.62 \\
\hline & $1.5-1.95$ & & $2.6-2.87$ & & $1.97-2.56$ & \\
\hline $\operatorname{Ex}(\mathrm{O} 2)$ & 2.45 & 111.54 & 6.49 & 25.93 & 5.19 & 63.81 \\
\hline & $1.57-3.32$ & & $5.7-7.29$ & & $3.94-6.44$ & \\
\hline As(F4) & 1.42 & 57.42 & 2.33 & 19.1 & 1.62 & 64.36 \\
\hline & $1.16-1.67$ & & $2.12-2.54$ & & $1.23-2.02$ & \\
\hline $\operatorname{Ex}(\mathrm{F} 4)$ & 2.31 & 152.76 & 5.59 & 46.01 & 3.51 & 123.9 \\
\hline & $1.23-3.39$ & & $4.43-6.77$ & & $1.94-5.09$ & \\
\hline$\Delta \mathrm{As}(\mathrm{O} 2 ; \mathrm{F} 4)$ & 0.08 & 694.97 & 0.1 & 144.96 & 0.16 & 561.22 \\
\hline & -0.36 & & $0.03-0.17$ & & -0.62 & \\
\hline$\Delta \operatorname{Ex}(\mathrm{O} 2 ; \mathrm{F} 4)$ & -0.01 & -19011 & 0.18 & 132.75 & 0.5 & 187.66 \\
\hline & -1.47 & & $0.07-0.3$ & & $0.15-0.86$ & \\
\hline IZ & 0.16 & 73.3 & 0.13 & 77.57 & 0.18 & 75.51 \\
\hline & $0.13-0.19$ & & $0.08-0.17$ & & $0.13-0.22$ & \\
\hline Age & 36 & 39 & 28 & 38 & 26 & 42 \\
\hline & $31-40$ & & $23-33$ & & $22-30$ & \\
\hline
\end{tabular}

Table 3: The summary table of the DAFCAR indexes at a depression (F3x on ICD-10, BHD) in comparison with sick boundary mental diseases (BPD) and healthy (Health). Right hemisphere.

\begin{tabular}{|c|c|c|c|c|c|c|c|c|c|c|c|c|}
\hline \multicolumn{13}{|c|}{ Aggregate Results T-tests; Grouping: Gender Group 1: men; Group 2: women } \\
\hline \multirow{2}{*}{ Index DAFCAR } & \multirow{2}{*}{ ICD-10 } & \multicolumn{2}{|l|}{ Mean } & \multirow[t]{2}{*}{ t-value } & \multirow{2}{*}{ df } & \multirow{2}{*}{$\mathbf{p}$} & \multicolumn{2}{|l|}{ Valid N } & \multicolumn{2}{|c|}{ Std.Dev. } & \multirow[t]{2}{*}{ F-ratio } & \multirow[t]{2}{*}{ p } \\
\hline & & Men & Women & & & & Men & Women & Men & Women & & \\
\hline As(F3) & \multirow{4}{*}{ Health } & 2.592 & 2.355 & 2.067 & 75 & 0.042 & 57 & 20 & 0.437 & 0.454 & 1.079 & 0.791 \\
\hline $\operatorname{Ex}(\mathrm{F} 3)$ & & 6.855 & 5.431 & 2.204 & 75 & 0.031 & 57 & 20 & 2.506 & 2.426 & 1.067 & 0.914 \\
\hline $\mathrm{As}(\mathrm{O} 2 ; \mathrm{F} 3)$ & & 0.019 & 0.097 & -2.105 & 75 & 0.039 & 57 & 20 & 0.146 & 0.135 & 1.158 & 0.749 \\
\hline $\mathrm{Ex}(\mathrm{O} 2 ; \mathrm{F} 3)$ & & -0.037 & 0.182 & -2.426 & 75 & 0.018 & 57 & 20 & 0.375 & 0.243 & 2.369 & 0.041 \\
\hline
\end{tabular}

Table 4: Statistical reliability of differences of the DAFCAR indexes in gender groups (statistically doubtful are excluded). Statistical 12.0 program.

\begin{tabular}{|c|c|c|c|c|c|c|c|c|c|c|c|c|}
\hline \multirow[t]{3}{*}{ Index DAFCAR } & \multicolumn{12}{|c|}{ Aggregate Results T-tests; Grouping: ICD Group 1: F3x; Group 2: Health } \\
\hline & \multirow[t]{2}{*}{ Gender } & \multicolumn{2}{|l|}{ Mean } & \multirow[t]{2}{*}{ t-value } & \multirow[t]{2}{*}{ df } & \multirow[t]{2}{*}{$\mathbf{p}$} & \multicolumn{2}{|l|}{ Valid $\mathbf{N}$} & \multicolumn{2}{|c|}{ Std. Dev. } & \multirow[t]{2}{*}{ F-ratio } & \multirow[t]{2}{*}{$\mathbf{p}$} \\
\hline & & $\mathbf{F} 3 \mathbf{x}$ & Health & & & & $\mathbf{F} 3 \mathbf{x}$ & Health & $\mathbf{F} 3 \mathbf{x}$ & Health & & \\
\hline Mo $f(O 2)$ & \multirow[t]{3}{*}{ Men } & 9.692 & 10.254 & -3.664 & 85 & $<0.001$ & 30 & 57 & 0.865 & 0.562 & 2.37 & 0.006 \\
\hline $\mathrm{As}(\mathrm{O} 2)$ & & 1.91 & 2.656 & -5.44 & 85 & $<0.001$ & 30 & 57 & 0.927 & 0.342 & 7.362 & $<0.001$ \\
\hline $\mathrm{Ex}(\mathrm{O} 2)$ & & 3.932 & 6.932 & -4.04 & 85 & $<0.001$ & 30 & 57 & 4.707 & 2.229 & 4.459 & $<0.001$ \\
\hline
\end{tabular}


Citation: Rosman SV (2018) Depression in the Context of Search of a New Paradigm in Psychiatry. Clin Depress 4: 134. doi: 10.4172/2572-0791.1000134

Page 6 of 9

\begin{tabular}{|c|c|c|c|c|c|c|c|c|c|c|c|c|}
\hline $\operatorname{Mo} f(F 3)$ & & 9.242 & 10.254 & -5.832 & 85 & $<0.001$ & 30 & 57 & 1.056 & 0.568 & 3.454 & $<0.001$ \\
\hline $\mathrm{As}(\mathrm{F} 3)$ & & 1.657 & 2.592 & -6.171 & 85 & $<0.001$ & 30 & 57 & 0.977 & 0.437 & 4.99 & $<0.001$ \\
\hline $\mathrm{Ex}(\mathrm{F} 3)$ & & 3.48 & 6.855 & -4.843 & 85 & $<0.001$ & 30 & 57 & 3.981 & 2.506 & 2.523 & 0.003 \\
\hline Mo $f(O 2 ; F 3)$ & & 0.533 & 0.035 & 4.814 & 85 & $<0.001$ & 30 & 57 & 0.776 & 0.088 & 78.471 & $<0.001$ \\
\hline Mo $f(O 2)$ & \multirow[t]{7}{*}{ Women } & 9.652 & 10.2 & -2.066 & 59 & 0.043 & 41 & 20 & 1.148 & 0.394 & 8.491 & $<0.001$ \\
\hline $\mathrm{As}(\mathrm{O} 2)$ & & 1.647 & 2.604 & -6.029 & 59 & $<0.001$ & 41 & 20 & 0.683 & 0.262 & 6.826 & $<0.001$ \\
\hline $\mathrm{Ex}(\mathrm{O} 2)$ & & 2.472 & 6.56 & -6.014 & 59 & $<0.001$ & 41 & 20 & 2.786 & 1.719 & 2.627 & 0.026 \\
\hline Mo f(F3) & & 9.201 & 10.163 & -3.22 & 59 & $<0.001$ & 41 & 20 & 1.297 & 0.424 & 9.373 & $<0.001$ \\
\hline $\mathrm{As}(\mathrm{F} 3)$ & & 1.431 & 2.355 & -4.635 & 59 & $<0.001$ & 41 & 20 & 0.83 & 0.454 & 3.34 & 0.006 \\
\hline $\operatorname{Ex}(\mathrm{F} 3)$ & & 2.238 & 5.431 & -3.825 & 59 & $<0.001$ & 41 & 20 & 3.32 & 2.426 & 1.872 & 0.143 \\
\hline Mo f(O2;F3) & & 0.61 & 0.038 & 2.997 & 59 & 0.004 & 41 & 20 & 0.848 & 0.092 & 85.704 & $<0.001$ \\
\hline \multicolumn{13}{|c|}{ Aggregate Results T-tests; Grouping: ICD Group 1: F3x Group 2: BPD } \\
\hline \multirow[t]{2}{*}{ Index DAFCAR } & \multirow[t]{2}{*}{ Gender } & Mean & Mean & \multirow[t]{2}{*}{ t-value } & \multirow[t]{2}{*}{ df } & \multirow[t]{2}{*}{$\mathrm{p}$} & Valid $\mathrm{N}$ & Valid N & Std.Dev. & Std.Dev. & \multirow[t]{2}{*}{ F-ratio } & \multirow[t]{2}{*}{$\mathrm{p}$} \\
\hline & & $\mathrm{F} 3 \mathrm{x}$ & BPD & & & & $F 3 x$ & BPD & $F 3 x$ & BPD & & \\
\hline Mo f(F3) & \multirow[t]{2}{*}{ Men } & 9.242 & 9.722 & -2.533 & 199 & 0 & 30 & 171 & 1.056 & 0.941 & 1.258 & 0.371 \\
\hline Mo $f(O 2 ; F 3)$ & & 0.533 & 0.292 & 2.425 & 199 & 0.1 & 30 & 171 & 0.776 & 0.693 & 1.254 & 0.377 \\
\hline $\mathrm{As}(\mathrm{O} 2)$ & \multirow[t]{2}{*}{ Women } & 1.647 & 2.158 & -2.982 & 69 & 0 & 41 & 30 & 0.683 & 0.753 & 1.214 & 0.562 \\
\hline $\mathrm{Ex}(\mathrm{O} 2)$ & & 2.472 & 5.239 & -3.778 & 69 & 0 & 41 & 30 & 2.786 & 3.376 & 1.469 & 0.257 \\
\hline
\end{tabular}

Table 5: Statistical reliability of differences of the DAFCAR indexes in the studied groups of diseases (statistically doubtful are excluded), Statistica 12.0 program.

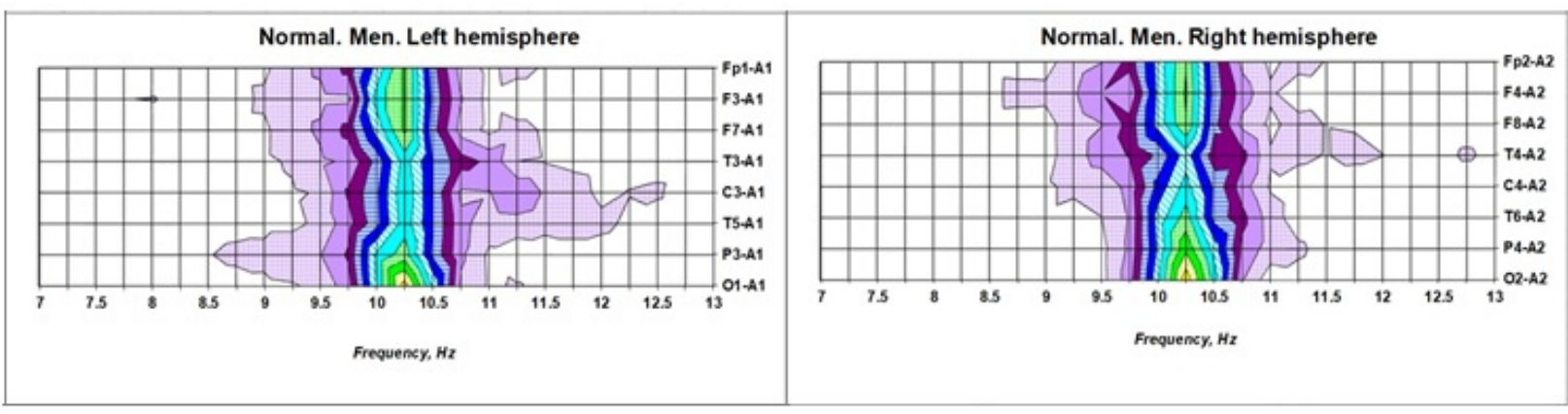

Figure 1: The dispersive cartogram of an alpha rhythm is normal. 
Citation: Rosman SV (2018) Depression in the Context of Search of a New Paradigm in Psychiatry. Clin Depress 4: 134. doi: $10.4172 / 2572-0791.1000134$

Page 7 of 9

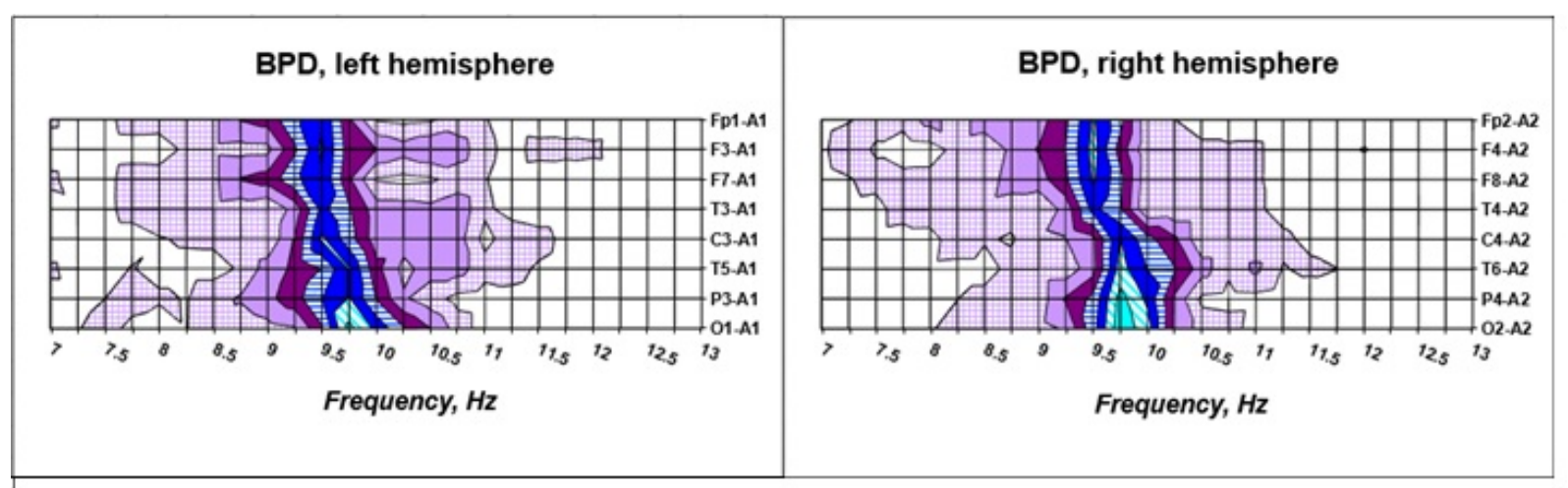

Figure 2: A dispersive cartogram of an alpha rhythm at boundary mental disorders (BPD).

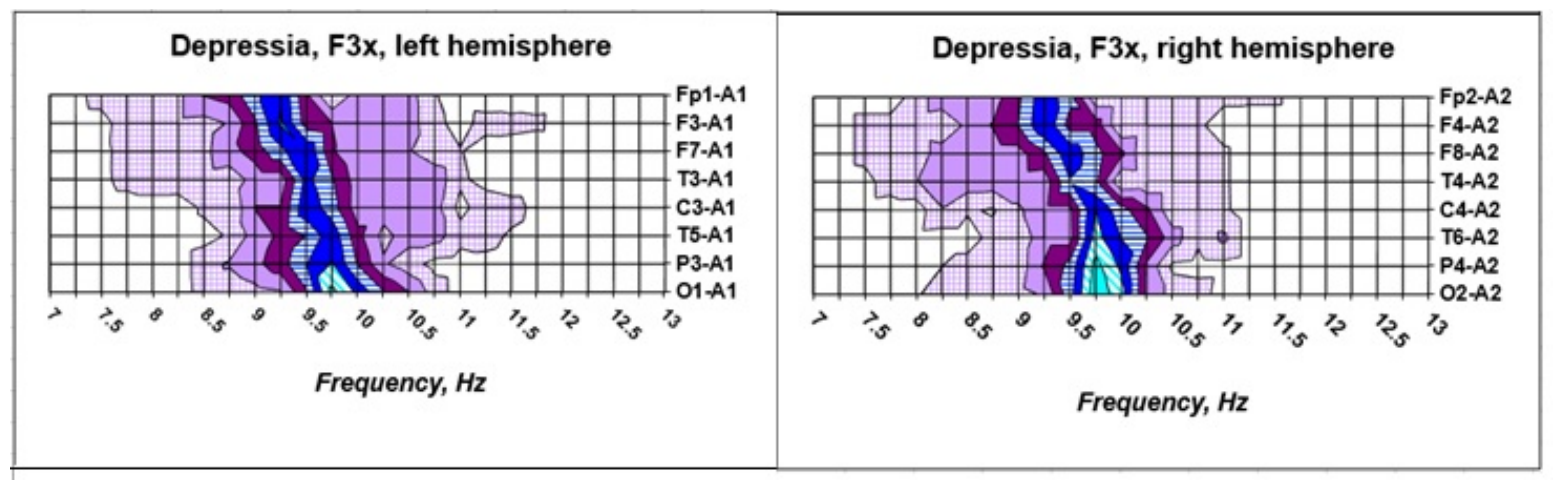

Figure 3: A dispersive cartogram of an alpha rhythm at a depression (F3x, BHD).

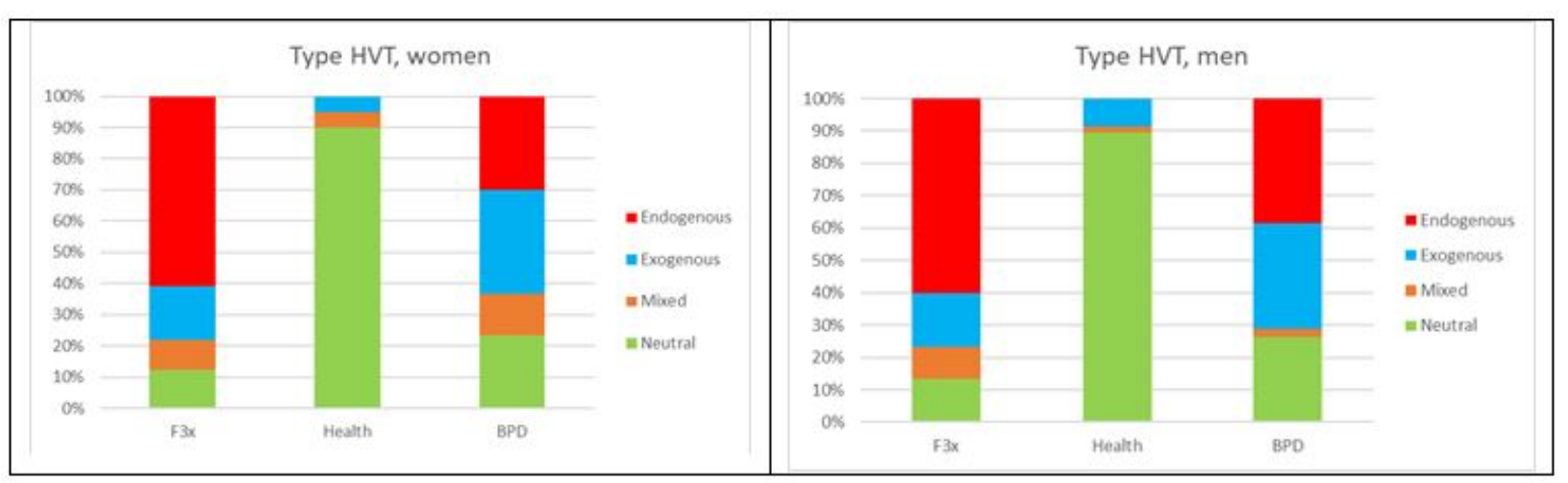

Figure 4: Comparative schedules of distribution of types of reaction to HVT in the studied groups.

\section{Discussion}

Preliminary statistical estimate of results of researches has resulted in the idea to compare a depression to a little studied class of boundary mental disorders especially as it was already covered in articles devoted to dispersion of an alpha rhythm [9]. These diseases there is enough various on the structure; some authors carry to them and a depression. We in this research 3 all structure of BPD have allocated depressive states therefore; generally there were organic cognitive violations (F06.x) and frustration of the personality (F60.x) which has entered into the BPD group.

The comparative analysis of statistical tables shows that there are no sexual and between hemispheres statistically significant differences in the DAFCAR parameters in the studied groups of diseases (Table 4), and therefore they aren't presented. There are some differences in the Healthy group. The reason of it is in the difficulties connected with 
search of mentally healthy people for researches. They can't be taken "from the street" - expert opinions that the person is mentally healthy are necessary. "Healthy men" in this research passed the examination which sometimes isn't connected with mental manifestations, for example, at conscription or at commission of offenses. At the same time "Healthy women" often had insignificant mental deviations, but as the commission of experts have been recognized healthy that is some convention which is shown in fluctuation of the DAFCAR indexes, especially indexes of a deviation of a range of an alpha rhythm from normal distribution (AS, Ex).

The general regularity characteristic both for depressions and for BPD the fact that they in parameters of the DAFCAR indexes deviate towards reduction in comparison with norm is. In feature it concerns indexes of a deviation of a range of an alpha rhythm from normal distribution (AS, Ex). The reason of it is quite clear if to adhere to the concept of fractal neurophysiology [10] and the dispersive analysis of an alpha rhythm. Here we deal with an initial stage of disorganization of Neuron-Glial Network of the brain when the amount of the neurons in her deviating neurophysiological parameters doesn't reach yet a certain critical threshold above which there comes the pathological polysemantic characteristic of the expressed psychopathology. I will remind that it agrees to the new paradigm of mental diseases offered by us [11], Neuron-Glial Network of the brain has to provide adequate processing of afferent information in which result adequate semantic images of surrounding reality on the basis of which socially acceptable scenarios of behavior of the personality are developed are developed. Disorganization of work of Neuron-Glial Network of the brain causes violation of this mechanism. On some, not quite still clear, to laws the similar state causes an overstrain of mechanisms of stabilization of activity of Neuron-Glial Network of the brain with violations in neurohumoral regulation of activity of a brain. All this also involves a dysphoria and a depression.
It is necessary to notice that the DAFCAR modal and frequency parameters undergo smaller changes: modal frequency of an alpha rhythm - almost normal, in frontal (Mo f F) - on border of tolerances in $0.5 \mathrm{~Hz}$, and at a depression these changes are statistically authentically more expressed in occipital assignments ( $M o f O$ ), than at BPD. Means, the depression is manifestation of more expressed disorganization of Neuron-Glial Network of the brain.

All described statistical changes are visually presented on dispersive cartograms of an alpha rhythm (Figures 1-3). Differences between norm and pathology are absolutely obvious. Delay of an alpha rhythm in frontal departments is very visually illustrated (increase in the $\Delta \mathrm{Mo}$ f parameter $(\mathrm{O} 2 ; \mathrm{F} 3))$ and increase of a deviation of distribution of power of a range of an alpha rhythm from normal (reduction of As, Ex).

Time introduces the amendments in views. In former works we submitted repeatedly the concept within "the theory of uniform psychosis" according to which psychopathological process progresses along "dementia axis" - from norm to dementia through frustration of the personality, light intellectual backwardness and schizophrenia with increase of dispersive violations of an alpha rhythm. A series of articles which has been published and devoted to psychopathology in the context of entropy of Neuron-Glial Network of the brain shows that some processes, in particular, schizophrenia and all diseases of "a schizoid circle", proceed in own way, to a special way, leading to dementia [12] sooner or later. The feature of this way is that at the same time are observed not total uniform disorganization of NeuronGlial Network of the brain, but uneven, with primary damage of frontal lobes. An initial stage of this process we also observe at a depression - the accruing dysfunction of frontal lobes, most often, a hypofrontality. The place of a depression (BHD) for "axis of dementia ", in the light of modern representations, is shown in Figure 4.

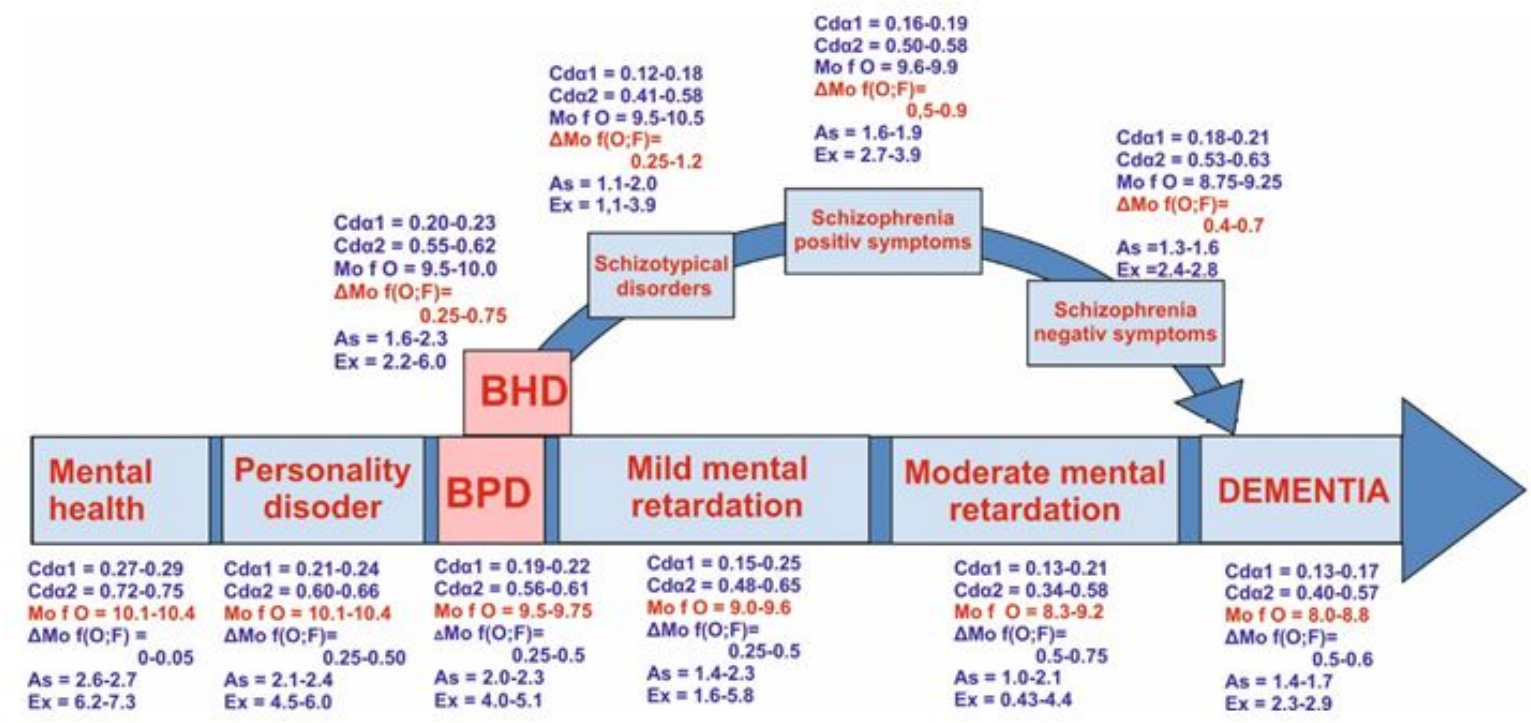

Figure 5: Place of F3x (BHD) on "axis of dementia" compliance indexes, DAFCAR and distribution of some of the major forms of mental illness.

The fact of existence in itself of a hypofrontality at a depression and schizophrenia isn't something new [13-15], however, the data existing in scientific literature still didn't become broad property of practical clinical physicians as relied or on categorial generalizations, or on 
difficult expensive researches. The DAFCAR method allows receiving the same results, as PET, however, by means of widely available EEG.

It is easy to notice that, moving ahead on "axis of dementia " across we observe, in the basic, the general decrease in frequency of an alpha rhythm, with gradual increase of a deviation of frequency in an alpha rhythm range from normal (Mo $\mathrm{f} \mathrm{O}$ ). "Splitting" in the place of transition to diseases of "a schizoid circle", followed by considerable delay of an alpha rhythm in frontal departments, begins with "bodyline hypofrontal disoder " (BHD), which is followed by the expressed depression with gradual increase of a difference between modal values in frontal and occipital departments $(\Delta \mathrm{Mo} \mathrm{f}(\mathrm{O} ; \mathrm{F}))$. We observe considerable dispersion of this parameter at Schizotypal personality disorder (STD, F21 in ICD-10). First, practically, this disease is schizophrenia ("inertly current schizophrenia" in former classifications). Secondly, usually at this diagnosis seek to avoid intensive antipsychotic therapy, i.e., in every possible way seek to delay the fact of decrease in the social status the patient, as creates effect of polymorphism of a clinic-neurophysiological picture. Thirdly, perhaps, it is also sign of difference between a debut of schizophrenia and schizoid frustration of the personality: at $\Delta \mathrm{Mo}$ f values $(\mathrm{O} ; \mathrm{F})>0.75$ the schizophrenia debut is most probable (Figure 5).

Along with it when progressing schizophrenia some reduction of $\Delta \mathrm{Mo} \mathrm{f}$ is observed $(\mathrm{O} ; \mathrm{F})$. Partially it is result of the carried-out treatment, but generally-owing to total delay of an alpha rhythm in all assignments-the main sign of process of dementia.

The analysis of HVT with use of DAFCAR according to Rosman shows what the prevailing reaction type at depressions, as well as at other diseases of "a schizoid circle", is endogenous (Figure 3). Consideration of the mechanism of types of reaction at HVT has to be a subject of more in-depth study, however in the present article it is possible to note that results of HVT confirm the fact of deep disorganization of Neuron-Glial Network of the brain of hypermarket which is followed by clinically expressed depression.

It is possible to assume that disorganization of Neuron-Glial Network of the brain, mainly in frontal departments, followed by violation of creation of adequate semantic images of surrounding, causes activation of mechanisms of normalization of her activity, generally a stressful link of neurohumoral regulation. The long increased tension of these mechanisms leads to decrease in their functional reserves which are shown a dysphoria and dementia.

Further disorganization of Neuron-Glial Network of the brain leads to development to the developed picture of the expressed deviant behavior [15-17] or a psychotic state.

\section{Conclusions}

The depression is a terrible symptom of the accruing disorganization of Neuron-Glial Network of the brain, mainly in frontal departments of hypermarket with formation of a functional hypofrontality.

Emergence of the expressed depressive syndrome demonstrates that functional reserves of an organism on compensation of the available disorganization in Neuron-Glial Network of the brain are exhausted, and processing of information will go on the way of pathological polysemantic with formation of socially unacceptable scenarios of behavior of the personality with psychotic symptomatology and rough deviant behavior.
The DAFCAR EEG method is a reliable, sensitive and available way of early diagnostics of these violations, providing the verified parameters of disorganization of Neuron-Glial Network of the brain with visualization of these changes on dispersive cartograms.

Search of new methods of restoration of disorganization of NeuronGlial Network of the brain considerably becomes simpler and becomes objective at application of the DAFCAR method.

Introduction of the DAFCAR EEG method will promote search of a new paradigm in psychiatry, complementing the categorical approaches existing in her with dimensional methods for the purpose of introduction her in evidential medicine.

\section{References}

1. Gaebel W, Becker T, Janssen B, Munk-Jorgensen P, Musalek M, et al. (2012) EPA guidance on the quality of mental health services. Eur Psychiatry 27: 87-113.

2. Sanislow CA (2016) Updating the research domain criteria. World Psychiatry 15: 222-223.

3. Maximova NE, Rosman SV, Civilian LV, Zabodayev SV (2016) Possibilities of use of dispersion of an alpha rhythm for screening verification of mental diseases. Ment Health 1: 16-25.

4. Rosman S (2017) The theoretical foundations of dispersion of amplitudefrequency characteristics of the alpha rhythm of the EEG. Glob J Add Rehab Med 2: 555-587.

5. Rosman S (2017) The use of analysis of variance of the alpha rhythm of the EEG in the study of the pathogenesis of alcoholism and the causes of alcoholic deliria. Glob J Add Rehab Med 2: 555-580.

6. Rosman SV (2013) Diagnostic capabilities of dispersion mapping the alpha rhythm of the electroencephalogram. Ment Health 6: 64-69.

7. Rosman SV (2014) Integral indexes of dispersion of amplitude-frequency characteristics of an alpha rhythm of an EEG in diagnosis of mental diseases. Ment Health 1: 132-135.

8. Rosman SV, Shpak LV (2013) New approaches to the assessment of polymorphism of the alpha rhythm EEG in psychiatric disorders. Ment Health 2: 39-44.

9. Rosman SV (2017) Borderline Personality Disorder in the Context of Entropy Neuron-Glial Networks of the Brain. Glob J Add Rehab Med 2: 555-595.

10. Rosman SV, Volkov VP (2015) Fractal theory of activity of the central nervous system and morphogenesis of internal organs. Med Pharmacol, No. 1 (14).

11. Rosman SV (2018) The «System 3+3» in a problem of searching of a new paradigm in psychiatry. Glob J Add Rehab Med 6: 555-676.

12. Rosman SV (2017) The Debut of Schizophrenia in the Context of Entropy Neuron-Glial Network of the Brane. Glob J Add Rehab Med 3: 555-617.

13. Andreasen NC, Rezai K, Alliger R, Swayze VW 2nd, Flaum M, et al. (1992) Hypofrontality in neuroleptic-naive patients and in patients with chronic schizophrenia. Assessment with xenon 133 single-photon emission computed tomography and the Tower of London. Arch Gen Psychiatry 49: 943-958.

14. Galynker II, Cai J, Ongseng F, Finestone H, Dutta E, et al. (1998) Hypofrontality and negative symptoms in major depressive disorder. J Nucl Med 39: 608-612.

15. Ivanov LB (2016) Psyco-phisiological interpretation of the functional state of the brain using EEG. Bullet Clinical Neurophysiology 1: 5-26.

16. Rosman S, Kurakhina O (2017) Violent Crime in the Context of Entropy Neuron-Glial Networks of the Brain. Glob J Add Rehab Med 2: 555-599.

17. Rosman SV (2017) Pedophilia in the Context of Entropy Neuron Glial Networks of the Brain. Glob J Add Rehab Med 4: 555-632. 